\title{
VICO, O DE LAS AGUAS PROFUNDAS
}

\section{Monica Riccio (ISPF, CNR)}

Resumen: Este es el breve relato de un descubrimiento, el de la Ciencia nueva de Vico, y el desvelamiento de la originalidad del análisis viquiano acerca del origen y de la evolución de la sociedad, del orden de la razón y de la organización política de la vida en común.

Palabras ClaVe: Vico, $350^{\circ}$ Aniversario, Scienza nuova, evolución humana, sociedad, democracia, M. Riccio.

\section{Vico, or about deep waters}

ABSTRACT: This is the brief account of a discovery, the one of the New science of Vico, and of the originality of the Vichian analysis of the origin and evolution of society, the order of reason and the political organization of life in common.

KeYwords: Vico, $350^{\text {th }}$ Anniversary, Scienza nuova, human evolution, society, democracy, M. Riccio.

\section{Vico, o delle acque profonde}

RIASSUNTO: Questo è il breve resoconto di una scoperta, quella della Scienza nuova di Vico, nonché della rivelazione dell'originalità dell'analisi vichiana circa l'origine e l'evoluzione della società, l'ordine della ragione e l'organizzazione politica della vita in comune.

PARole ChiaVE: Vico, $350^{\circ}$ Anniversario, Scienza nuova, evoluzione umana, società, democrazia, M. Riccio.

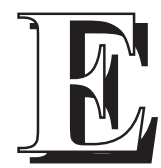

n las páginas, en los textos viquianos, en el proceso de investigación infatigable hasta llegar a las tres redacciones de la Scienza nuova, fue necesario entrar: cruzar un umbral, arañar una superficie que a mí, hace muchísimos años, cuando me acerqué a ello con cautela, me pareció dura y resbaladiza, impenetrable. Pronto descubrí que era como la superficie del agua: la lectura fue enseguida, tuvo que ser, inmersión. Lectura que engancha, infinitamente, y lectura filosófica en grado sumo, que sin embargo no se asemeja a ninguna otra. 
«Lo que resulta interesante de la filosofía»-decía Deleuze- «es que propone un corte de las cosas, un nuevo corte: ella reúne en el mismo concepto cosas que uno diría que son muy diversas y separa otras muy próximas». ${ }^{1}$

En Vico encontré esta filosofía, ejercicio ingenioso que hunde la mirada en cosas lejanas, invisibles, se diría que inencontrables, en el corazón del hombre, en las antigüedades desaparecidas, en el inicio del pensar humanamente, en el primer aviso del cielo, en el difícil, contradictorio formarse y desarrollarse de las sociedades humanas. Ejercicio filosófico que me enganchó como ningún otro estudio, como ningún otro autor. Y lo hizo también con el reclamo de aquel trabajo incesante sobre la Scienza nuova, arreglos, correcciones, mejoras, añadidos, la materia de los filólogos que yo, como muchos jóvenes estudiosos de la filosofía, juzgaba distante; estaba poco convencida, en suma, del nexo entre filosofía y filología. La distancia también disminuyó gracias a una visita a la sección de manuscritos de la Biblioteca Nacional de Nápoles: acompañé a Paolo Cristofolini, que trabajaba con Manuela Sanna en la edición crítica de la Scienza nuova de 1730, y fue él quien guió mi mirada, quien me hizo ver de verdad las "correcciones, mejoras y añadidos" a la Scienza nuova. Vi el crecer fatigoso sobre las páginas de aquella profundidad, el cincel, los cambios, los «diseños» buscados y difícilmente encontrados en esa inmensa materia.

La Scienza nuova era leída verdaderamente «como si no hubiese libros en el mundo», ${ }^{2}$ pero en la red de las referencias, en los ajustes de los conceptos -correcciones y añadidos, a pluma, a mano, sobre hojitas de papel encolado donde el espacio de la página estaba ya saturado- intuí claves de acceso, resquicios, hilos que se devanan; el trabajo sobre la página impresa -de lectura, de inmersión- siempre debió y quiso tener en cuenta las profundidades que esa tarea indicaba.

Años después volví a ver esos manuscritos siguiendo las trazas y las variaciones de un pasaje crucial: el «consejo» de Solón a los plebeyos, la invitación a reconocerse de igual naturaleza a la de los nobles $\mathrm{y}$, por tanto, a pedir iguales derechos. Pasaje crucial porque conduce desde los tiempos heroicos a los tiempos humanos, desde un gobierno de pocos a un gobierno de muchos o de todos y, a la vez, finalmente, al reconocimiento de la naturaleza humana razonable, para todos. ${ }^{3}$

Se concentran, en pocos renglones, algunos de los elementos que provocan la absoluta originalidad del análisis viquiano del origen y de la evolución de la sociedad. Siempre me he guiado por la sensación de maravilla ante esa originalidad

1. Gilles Deleuze, entrevista de Hérvé Guibert, Le Monde 6 de octubre de 1983.

2. G. Vico, Principi di Scienza nuova 1744 (de ahora en adelante SN44), en Opere, a cargo de A. BatTistini, Mondatori, Milán, 1990, I, p. 541 [§ 330].

3. Cfr. G. VICO, Princìi di una scienza nuova intorno alla natura delle nazioni per la quale si ritrovano i principi di altro sistema del diritto naturale delle genti (1725), en Opere, cit., II, p. 1.097 [§ 242]; SN44, pp. 593-595 [§§ 414-416]. 
fatigosamente construida, que buscaba los principios de la asociación humana, de su devenir, en la naturaleza oscura y lejanísima de los primeros hombres, naturaleza incapaz de "entendimiento" que nosotros, a nuestra vez, podemos entender solo a «duras penas»; 4 principios, por tanto, que no residen en ninguna intención, ya que incluso en las repúblicas aristocráticas «las mentes de los hombres, siendo particularísimas, no podían naturalmente entender el bien común». ${ }^{5}$

El curso de las naciones diseñado por Vico transcurre durante buena parte sobre la incapacidad de concebir lo común -sobre una natural, humana indecisióny no obstante sobre el impulso igualmente natural de construirlo y de mantenerlo.

Incluso cuando luego, «finalmente», los hombres llegan universalmente a apropiarse de la razón que les pertenece desde siempre, en los tiempos de la «razón totalmente desplegada», esta no es nunca dada "por descontado", como en las teorías contractualistas. Esto también permite pensarla como razón de todos y hacer de ella el sostén, el "alma" de los «gobiernos humanos», repúblicas populares y monarquías.

Cuando en las hipótesis contractualistas sobre el tema de la "participación" de todos en la esfera pública se instala el silencio de la omnipotencia del contrato, se abre en la Scienza nuova viquiana un campo de reflexión riquísimo.

Ahí puede verse de un modo nuevo la expansión, el proceso ascendente, la luz de una humanidad razonable y por eso mismo igualada; al mismo tiempo la difícil capacidad de la razón que es de todos, pero no abandona nunca, y no podría, la inclinación a la singularidad, a lo particular, la concreción del cuerpo y de los afectos. También pueden verse con claridad, y comprenderse, las mediocridades y las debilidades de una colectividad que razona y que gobierna; las dificultades, hasta la imposibilidad, de una reflexión colectiva.

Se abren, pues, perspectivas nuevas sobre la problematicidad de la asociación entre iguales, problematicidad a menudo eludida en la teoría, y en la práctica, de la democracia representativa. El diseño viquiano del gobierno de todos, desde una distancia y diversidad ciertamente extrema, desde su "atraso", indica -de esto siempre he estado convencida- elementos preciosos de análisis de las democracias.

He seguido la trayectoria de conceptos que sostienen este diseño, desde las Oraciones inaugurales a las "Ciencias nuevas": por consiguiente, el iter del concepto de razón de Estado, gravado por el recelo de una «sabiduría culta», razón de pocos. Más tarde, y más detenidamente, el itinerario de las figuras del colectivo -multitud, plebe, pueblo, vulgo-y la "dialéctica" de los pocos y de los muchos en el seno de la comunidad.

$\mathrm{A} 1$ recorrer las líneas de la incesante búsqueda viquiana de «orden», un elemento ha adquirido particular resonancia: la necesidad, acentuada en la Scienza 
nuova de 1744, de vivir cada fase, cada tiempo, completamente. La duración y la grandeza de Roma se deben, también a los precisos y «lentos pasos» de los Romanos, a la lentitud con la que supieron prolongar el heroísmo hasta el tránsito, ya maduro, hacia los «tiempos humanos», hacia la libertad popular. En Grecia, por el contrario, fue la filosofía la que apresuró el curso de las naciones, condenando su propio esplendor a un fin precoz.

La búsqueda viquiana, búsqueda filosófica en sumo grado, ha podido engancharme todo este tiempo además por la invitación, que ella repite en todas sus partes y en todo momento, a la lentitud, a la pausa, a los precisos y «lentos pasos».

[Traducción del italiano por María José Rebollo Espinosa]

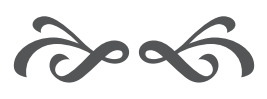

